\title{
Colon specific polyelectrolyte complexation based formulations of losartan potassium for effective management of hypertension
}

\begin{abstract}
Losartan Potassium is an angiotensin II receptor antagonist (AIIRA) with antihypertensive activity. It is used in the management of hypertension and heart failure. The main purpose of the study was to formulate and evaluate a colon specific polyelectrolyte complexation based formulations of Losartan Potassium (LP). The polyelectrolyte complexes were prepared by physical mixing of cationic Chitosan(C) in combination with anionic polyanions like Xanthan gum(X)/Sodium alginate (SA). The polyelectrolyte complex (PEC) blend were incorporated into Hydroxy propylmethylcellulose (HPMC) capsules (\# 0) and the capsule were coated with the solution of Eudragit S $100(1-5 \% \mathrm{w} / \mathrm{v})$ by dip coating method to safeguard the release of drug in the upper gastrointestinal tract. The powder blends were evaluated for their additive properties. FTIR spectroscopy of physical mixture of Drug and polymer (1:1) exhibited no interaction with the drug as major peaks of the drug were found to be intact in the spectra. The blend of all the batches were evaluated for parameters like angle of repose was found to be between 18.5-19.7, Bulk density was found to be between $0.172-0.2(\mathrm{gm} / \mathrm{cc})$ and tapped density between $0.183-0.218(\mathrm{gm} / \mathrm{cc})$. Carr's Index was found to be in between 3.17-14.7, Hausner's ratio ranged between 1.03-1.16. All the formulations showed excellent blend properties. Prepared coated capsules were evaluated for physical parameters like percent swelling index and vitro drug release. Percent swelling index suggested that Eudragit S-100 at $5 \% \mathrm{w} / \mathrm{v}$ concentration was found to have best percent swelling index accounting to highest value of $122 \%$ after twelve hours of study. Dissolution study suggested that the F5 formulation comprising Chitosan $+\mathrm{SA}(50 \mathrm{mg}+20)$ showed the highest drug release i.e $98.92 \%$ in $15 \mathrm{hrs}$ at $\mathrm{pH} 7.4$ phosphate buffer with regard to release kinetics, the data were best fitted with the first order kinetics with super case II release kinetics. From the data, it was suggested that Chitosan/Alginate based polyelectrolyte complex may constitute an excellent carrier for colonic drug delivery system (CDDS).
\end{abstract}

Keywords: CDDS, polyelectrolyte complex, eudragit S-100, chitosan, sodium Alginate, xanthan gum
Volume 5 Issue I - 2018

Shashank Chaturvedi, Sumbul Ayaz

Department of Pharmaceutics, Invertis University Bareilly, India

Correspondence: Shashank Chaturvedi, Department of Pharmaceutics, Faculty of Pharmacy, Invertis University Bareilly, Invertis Village $\mathrm{NH}-24$ Bareilly Lucknow National Highway Bareilly U.P. India, Tel 9808904682, Email shashank.c@invertis.org

Received: January 19, 2018 | Published: February 08, 2018
Abbreviations: AIIRA, angiotensin ii receptor antagonist; LP, losartan potassium; SA, sodium alginate; $\mathrm{PEC}$, polyelectrolyte complex; HPMC, hydroxy propyl methyl cellulose; CDDS, colonic drug delivery system; FTIR, fourier-transform infrared spectroscopy

\section{Introduction}

The colon targeted drug delivery system has a number of important implications in the field of pharmacotherapy. Oral colon targeted drug delivery system has recently gained importance for delivering a variety of therapeutic agents for both local and systemic administration targeting of drugs to the colon via oral administration protect the drug from degradation or release in the stomach and small intestine. It also ensures abrupt or controlled release of the drug in the proximal colon. Various drug delivery systems have been designed that deliver the drug quantitatively to the colon and then trigger the release of drug. ${ }^{1}$ The new techniques of drug delivery which makes the system capable of controlling the rate of drug delivery, sustaining the duration of therapeutic action and most focused on targeting the drugs to the specific sites have aroused as revolution in pharmaceutical field, thereby giving rise to the novel drug delivery system. ${ }^{2}$ The electrostatic interactions between two or more opposite charged polyelectrolyte in solution form complex are called as polyelectrolyte complexes. ${ }^{3,4}$ It involves interaction between the polymer-polymer, polymer-drug, and polymer-drug-polymer. ${ }^{5}$

These are formed due to electrostatic interaction between oppositely charged polyions. This avoids the use of chemical crosslinking agents, thereby reducing the possible toxicity and other undesirable effects of the reagents. The polyelectrolyte complexes formed between a poly acid and poly base are little affected by the $\mathrm{pH}$ variation of the dissolution medium This concept of complexation, between DNA and Chitosan. ${ }^{6}$ Many approaches have been developed to manufacture polyelectrolyte complex like Polyelectrolyte Titration, Jet Mixing, Ionic gelation method, Hot-melt Extrusion method etc. Losartan potassium is a potent highly specific angiotensin II type (AT1) receptor antagonist with anti-hypertensive activity. It develops a gradual and long lasting effect as antihypertensive, becoming a new alternative to this frequent chronic disease treatment. ${ }^{7}$ The ARBs specifically block the interaction of angiotensin II at the AT1 receptor, thereby relaxing smooth muscle, increasing salt and water excretion, reducing plasma volume, and decreasing cellular hypertrophy. These 
agents exert their blood pressure-lowering effect mainly by reducing peripheral vascular resistance usually without a rise in heart rate. ${ }^{8}$

\section{Materials and methods}

\section{Materials}

Losartan Potassium was gifted by, ZIM Laboratories Nagpur. Eudragit S100 was gifted from EVONIK, India. PEG 400, Sodium Alginate, Chitosan and Talc were purchased from Central Drug House (Pvt.) Ltd, India; Xanthan gum was purchased from Yarrow chem. products Mumbai, India. All other ingredients used were of analytical grade.

\section{Method}

Preparation of polyelectrolyte complex: Polyelectrolyte based colon specific formulation of (LP) were prepared by different polyelectrolytes were physically blended with different ratios and the calculated amount of drug + polyelectrolyte physical mixture was then passed through sieve no 60 and filled into the HPMC (\# 0) size capsules as per the different ratios of polymers were shown in the formulation Table 1.

Preparation of entero-specific coating solution: Coating solution was prepared and shown in Figure 1.

Table I Formulation of controlled release capsule by physical blending method

\begin{tabular}{lllll}
\hline Formulations & $\begin{array}{l}\text { Chitosan } \\
(\mathbf{m g})\end{array}$ & $\begin{array}{l}\text { Xanthan } \\
\text { gum } \mathbf{( m g )}\end{array}$ & $\begin{array}{l}\text { Sodium } \\
\text { alginate }(\mathbf{m g})\end{array}$ & $\begin{array}{l}\text { LP } \\
\mathbf{( m g})\end{array}$ \\
\hline FI & 100 & 5 & - & 50 \\
F2 & 100 & 10 & - & 50 \\
F3 & 100 & 15 & - & 50 \\
F4 & 50 & - & 10 & 50 \\
F5 & 50 & - & 20 & 50 \\
F6 & 50 & - & 30 & 50 \\
\hline
\end{tabular}

Evaluation of polyelectrolyte physical mixture: The prepared polyelectrolyte physical mixtures were evaluated for FTIR, bulk density, tapped density, Carr's index, hausner's ratio and angle of repose.

Characterization of pre-compressed powder blend: ${ }^{9-12}$ Pre-compressed powder blend properties were evaluated on the basis of following parameters which are mentioned below:

a. Bulk density: The bulk density value includes the volume of all the pores within the sample. Accurately weighted quantities of powder were transferred into measuring cylinder and initial volumes were measured. The bulk density was calculated by using following formula.

Bulk Density $(\mathrm{BD})=\frac{\text { Weight of the powder sample }}{\text { Volume of the powder sample }}$

b. Tapped density: The tapped value, or absolute density, of a sample excludes the volume of the pores and voids within the sample. Accurately weighted quantities of powders were transferred into measuring cylinder. The cylinders were then allowed to tap on to a bulk density apparatus for 100 times. The heights of tapped powders were measured, and then the tapped density was calculated by using following formula.

$$
\text { Tapped Density }(\mathrm{TD})=\frac{\text { Weight of the powder sample }}{\text { Volume of the tapped powder sample }}
$$

c. Carr's index and hausner's ratio: The Carr's index and the Hausner's ratio were determined by measuring both the bulk density and tapped density of the powder. The Carr's and Hausner's ratio were calculated for all the formulations as follows:

$$
\begin{aligned}
& \text { Carr's index }=\frac{\text { Tapped Density }- \text { Bulk Density }}{\text { Bulk Density }} \times 100 \\
& \text { Hausner's Ratio }=\frac{\text { Tapped Density }}{\text { Bulk Density }}
\end{aligned}
$$

d. Angle of repose: The frictional force in a loose powder can be measured by the angle of repose $(\theta)$. Angle of repose is defined as the maximum angle possible between the surface a pile powder and horizontal plane. The angle of repose of powder will be determined by fixed funnel method to access the flow property of powders. The diameter of the powder cone (d) and the height (h) of the pile were noted. From the diameter, radius (r) was calculated. The angle of repose $(\theta)$ was calculated by using following formula.

è $=\tan ^{-1} h / r$

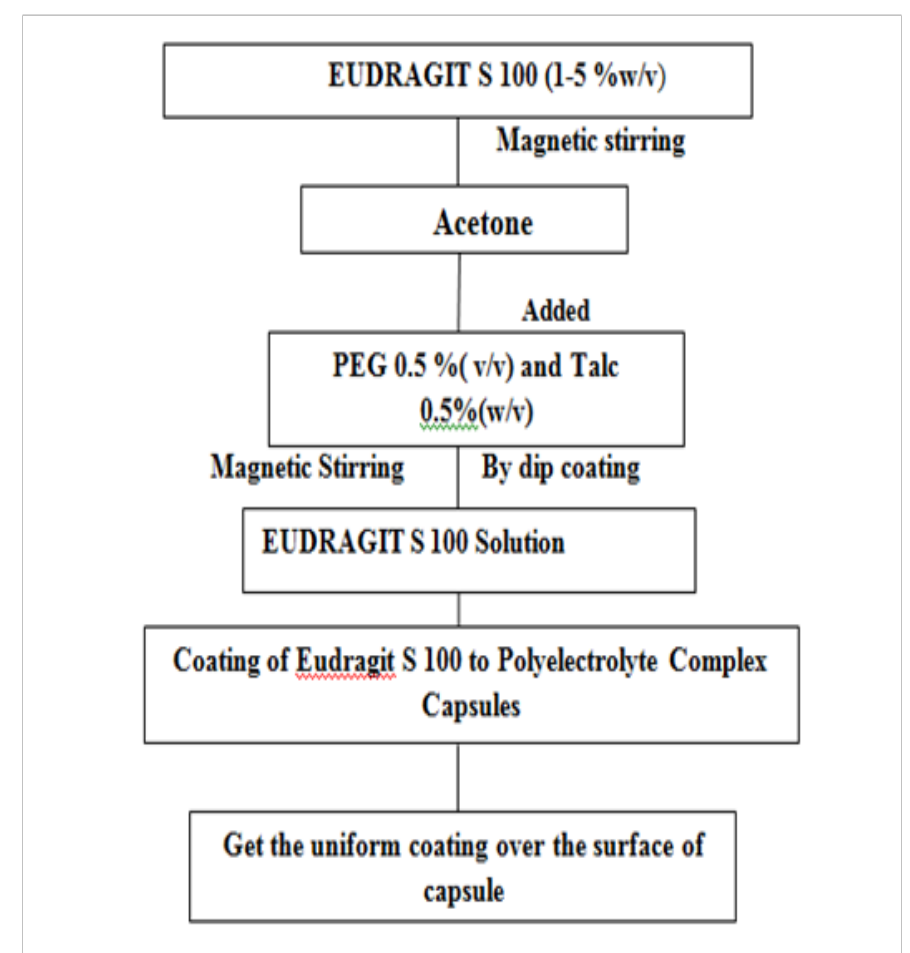

Figure I Schematic representation for preparation of coating solution. 
Evaluation parameters of coated capsule: The prepared coated capsules were evaluated on the following parameters like:

a. Coating thickness: The prepared colon specific coated capsules were evaluated for the thickness attained by Eudragit S100 coating. The thickness was measured by Micrometer Screw gauge. Initially, the bare capsule shells were subjected for thickness measurement at three different positions. This was followed by final measurement at three different positions of the coated capsules. The changes in thickness indicate the final Eudragit coating acquired by the capsules. The evaluation was done in triplicate. ${ }^{13}$ Coating thickness was calculated by using this formula.

Coating thickness $=$ Thickness of coated capsule - Thickness of bare capsule

b. \% Swelling index: The swelling studies were carried out of the formulations, i.e., from F1 to F6 as described by Mundargi et al. ${ }^{14}$ with slight modification. Three capsule from each batch were weighed initially and immersed in different dissolution medium ( $\mathrm{pH} 1.2,6.8$, and 7.4) using USP type II dissolution apparatus in $900 \mathrm{ml}$ dissolution medium at $50 \mathrm{rpm}, 37^{\circ} \mathrm{C} \pm 0.5^{\circ} \mathrm{C}$. The swollen capsules were taken out at predetermined time in tervals, and using tissue paper, excess of water on their surface was carefully removed and capsules were reweighed (W2). The study was carried out over a period of $12 \mathrm{~h}$ and the capsules were observed for rupturing. The $\%$ swelling index was calculated using the following formula which is mentioned below.

$\%$ Swelling index $=\frac{\text { Wet weight of capsule }- \text { Dry weight of capsule }}{\text { Dry weight of capsule }} \times 100$

\section{In - vitro evaluation of capsule formulations}

Capsule formulations were evaluated on the following parameters:
a. Weight variation test
b. Drug content.
c. In vitro drug release.
d. Stability studies.

\section{Weight variation test ${ }^{15}$}

20 capsules were selected at random. One capsule was weighed. The capsule was opened and the contents were removed as completely as possible. The emptied shells were weighed. The net weight of its content was determined, that was by subtracting the weight of the shells from the weight of the intact capsule. The procedure was repeated with other 19 capsules. Every individual capsule in a batch should be uniform in weight and weight variation should be within the permissible limits.

$$
\% \text { wt variation }=\frac{\text { Individual weight }- \text { Avg. weight }}{\text { Avg.weight }} \times 100
$$

\section{Drug content ${ }^{16}$}

Weighed an amount of the equivalent to $50 \mathrm{mg}$ of Losartan potassium was dissolved in $100 \mathrm{ml}$ of phosphate buffer $\mathrm{pH} 7.4$, filtered, diluted suitably and analyzed for the drug content at $228.5 \mathrm{~nm}$ using UV-visible spectrophotometer.

\section{In - vitro drug release ${ }^{13,17}$}

Drug release studies of the prepared colon specific capsule by using polyelectrolyte complex were performed in accordance with the method by Newton et al. ${ }^{16}$ and Ganesh B Patil et al. ${ }^{12}$ with slight modification in triplicate, in a USP Dissolution Apparatus II (Paddle type) (Electro lab TDT-08Lx, India). The dissolution test was performed using $0.1 \mathrm{~N} \mathrm{HCl} \mathrm{pH} 1.2$ for the first 2 hours, followed by in phosphate buffer $\mathrm{pH} 6.8$ for next $2 \mathrm{hr}$ at $37 \pm 0.5^{\circ} \mathrm{C}$. The media was then replaced by phosphate buffer $\mathrm{pH} 7.4$ and the release was observed for up to $11 \mathrm{hrs}$ in the 7.4 phosphate buffer. The speed of rotation of paddle was set at $50 \mathrm{rpm}$. Aliquots of $1 \mathrm{ml}$ were withdrawn from the dissolution medium at different time intervals, filtered and fresh dissolution medium was replenished immediately. Absorbance after dilutions was observed by UV spectrophotometer (LABINDIA-3200) at maximum wavelength.

\section{Stability studies}

Stability studies were carried out on best formulation. The capsules were stored at $40^{\circ} \mathrm{C}$ and $75 \% \mathrm{RH}$ for duration of three months. After every one month samples were withdrawn and tested for various parameters like drug content and in vitro drug release. ${ }^{18}$

\section{Results and discussion}

\section{Drug-excipients compatibility studies}

FT-IR studies: The FT-IR spectra of pure losartan potassium revealed the presence of characteristic peaks of drug such as off $-\mathrm{C}-\mathrm{O}-\mathrm{C}$ stretching (Ether linkage) at $1003 \mathrm{~cm}^{-1},-\mathrm{C}-\mathrm{Cl}$ bending at $1254.75 \mathrm{~cm}^{-}$ 1, $\mathrm{C}=\mathrm{C}$ stretching at $1490.07 \mathrm{~cm}^{-1},-\mathrm{N}=\mathrm{N}$ stretching at $1526 \mathrm{~cm}^{-1}, \mathrm{CH}$ Stretching (aromatic) at $2935 \mathrm{~cm}^{-1}$ and-O-H stretching (hydroxyl group) at $3446.84 \mathrm{~cm}^{-1}$. The FTIR spectra of physical mixture of

a. Drug and Xanthan gum, (1:1) exhibited no interaction with the drug as major peaks of the drug were found to be intact as depicted in the FTIR spectra. The absorption band due to $-\mathrm{C}-\mathrm{O}-\mathrm{C}$ $\left(1007.85 \mathrm{~cm}^{-1}\right),-\mathrm{C}-\mathrm{Cl}$ bending $\left(1257.64 \mathrm{~cm}^{-1}\right),-\mathrm{N}=\mathrm{N}$ stretching $(1641.49) \mathrm{cm}^{-1},-\mathrm{C}-\mathrm{H}$ stretching $\left(2937.71 \mathrm{~cm}^{-1}\right),-\mathrm{O}-\mathrm{H}$ stretching $\left(3226.08 \mathrm{~cm}^{-1}\right)$.

b. The FTIR spectra of drug and sodium alginate showed the absorption band due to $-\mathrm{C}-\mathrm{O}-\mathrm{C}\left(1004.96 \mathrm{~cm}^{-1}\right),-\mathrm{C}-\mathrm{Cl}$ bending $\left(1258.61 \mathrm{~cm}^{-1}\right),-\mathrm{N}=\mathrm{N}$ stretching $\left(1573.02 \mathrm{~cm}^{-1}\right),-\mathrm{C}-\mathrm{H}$ stretching $\left(2940.61 \mathrm{~cm}^{-1}\right),-\mathrm{O}-\mathrm{H}$ stretching $\left(3450.80 \mathrm{~cm}^{-1}\right)$.

c. The FTIR spectra of drug and chitosan showed the absorption band due to $-\mathrm{C}-\mathrm{O}-\mathrm{C}\left(1015.57 \mathrm{~cm}^{-1}\right),-\mathrm{C}-\mathrm{Cl}$ bending $\left(1114.90 \mathrm{~cm}^{-1}\right),-\mathrm{N}=\mathrm{N}$ stretching $\left(1539.26 \mathrm{~cm}^{-1}\right),-\mathrm{C}-\mathrm{H}$ stretching to $\left(2929.03 \mathrm{~cm}^{-1}\right),-\mathrm{O}-\mathrm{H}$ stretching to $\left(3484.56 \mathrm{~cm}^{-1}\right)$. The above findings suggest that there was no interaction between drug and polymer, although there was slight shift in the peaks in the FT-IR spectra but considered to be insignificant shown in Figure 2.

Evaluation of powder blend: The blend of all the batches were evaluated for parameters like angle of repose was found to be between 18.5-19.7 Bulk density was found to be between $0.172-0.2(\mathrm{gm} / \mathrm{cc})$ and tapped density between $0.183-0.218(\mathrm{gm} / \mathrm{cc})$. Carr's Index was found 
to be in between 3.17-14.7, Hausner's ratio ranged between 1.03-1.16. All the formulations showed excellent and good blend properties has been shown in Table 2 .

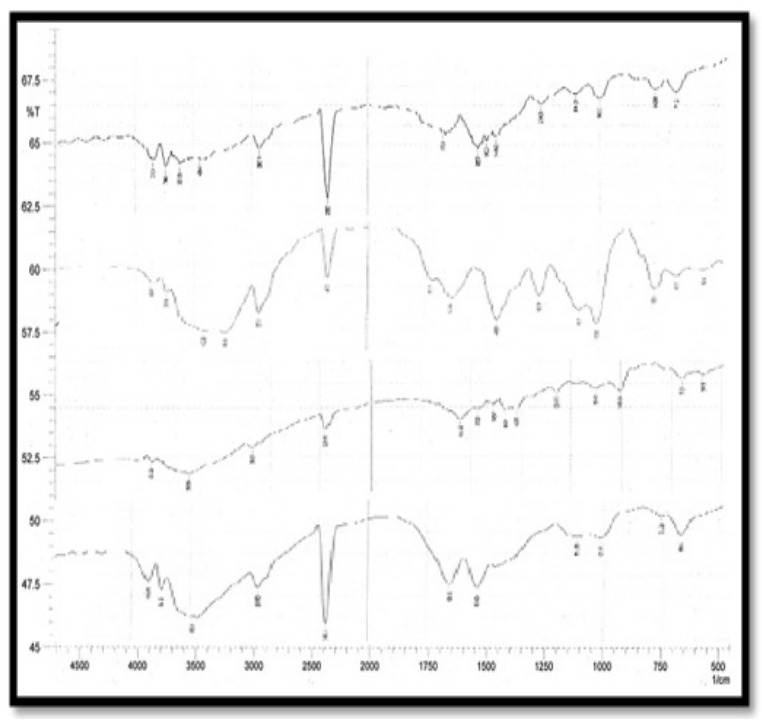

Figure 2 FT-IR spectra of drug with polymer.

\%Swelling Index: The effect of Eudragit S-100 (1-5 \% w/v) concentration as colon specific coat over HPMC capsules was investigated by swelling index. The coated capsules $(1-5 \% \mathrm{w} / \mathrm{v})$ were introduced in different dissolution medias ( $\mathrm{pH} 1.2,6.8$ and 7.4). The increase in Eudragit S-100 concentration exhibited direct relationship with swelling index. In all the formulations it was observed that Eudragit S-100 was able to withstand the integrity of the capsule in different $\mathrm{pH}$ conditions, though concentrations ranging from $(1-3 \% \mathrm{w} / \mathrm{v})$ showed very less $\%$ swelling index it was less than $30 \%$ in first four hours. On further increasing the concentration it was found that the $\%$ swelling index was further decreased and it accounted only to about $19 \%$ and $14 \%$ for concentrations $4 \& 5 \% \mathrm{w} / \mathrm{v}$ respectively for first four hours. The increment in the concentration accounted more \% swelling index which can be because of the increased amount of Eudragit S-100 a colon specific polymer. Therefore on the basis of \% swelling studies Eudragit S-100 at $5 \% \mathrm{w} / \mathrm{v}$ concentration was found to have best percent $\%$ swelling index accounting to highest value of $122 \%$ after twelve hours of study which might improve the drug release after the formulation reach to the colonic environment shown in Figure 3. The percentage swelling index has been shown in Table 3 .

Drug content, thickness and average weight: Results for drug content, thickness and weight variation are indicated in Table 4 and were found to be well within the limits. Drug content of all the formulations were determined and it was found to be in the range of 98.80-101.96 $\%$ for all the formulations. The drug content results were found to be in compliance with the range of drug content of I.P. Thickness of all the formulation of coated capsule were found to be in the range between 2-3.2 (mm) has been shown in Table 4.

In-vitro drug release profile: In vitro drug release studies were performed for all the formulations at varying $\mathrm{pH}$ conditions such as $\mathrm{pH} 1.2$ $(0.1 \mathrm{~N} \mathrm{HCl})$, phosphate buffer $\mathrm{pH} 6.8$ and $\mathrm{pH} 7.4$ to mimic the physiological $\mathrm{pH}$ conditions. The Eudragit S 100 coated capsules (F1-F6) were introduced in the dissolution media for the release studies of drug in the different $\mathrm{pH}$ environment. The result demonstrated that all the prepared formulations were able to sustain the release of the drug efficiently over the span of 15 hours which might be an exhibition of PEC formation between different polyions. Almost all the formulation exhibited less than $2 \%$ and $6 \%$ drug release within first two hours and first four hours of study respectively. The very less amount of drug release shown by the formulations in first four hours might be in relation to the colonic (pH sensitive 7.4) release properties of Eudragit $\mathrm{S}-100$. As the formulations were assessed for the effect of change of $\mathrm{pH}$ ( $\mathrm{pH} 1.2$ to $\mathrm{pH} 6.8$ and then to 7.4) the coating of the capsules might have dissolved which is in correlation with release profiles. Almost all the formulations started releasing the drug in phosphate buffer $\mathrm{pH} 7.4$ for upto 15 hours with formulation F5 showing maximum $98 \%$ The formulation containing Chitosan and Xanthan Gum F1-F3 (Chitosan 100mg and 5mg Xanthan gum), F2 (Chitosan 100mg and 10mg Xanthan Gum), F3 (Chitosan $100 \mathrm{mg}$ and $15 \mathrm{mg}$ Xanthan gum) released $95.65 \%, 91.47 \%$ and $95.54 \%$ of the drug, respectively up to $15 \mathrm{hr}$ of the dissolution study. The sustained release profile as exhibited by the formulations containing (Chitosan and Xanthan Gum) as polyions might be due to polyelectrolyte complexation. By increasing the concentration of Xanthan Gum with Chitosan the drug release was further decreased moreover it can only release the drug maximum to $95.65 \%$.

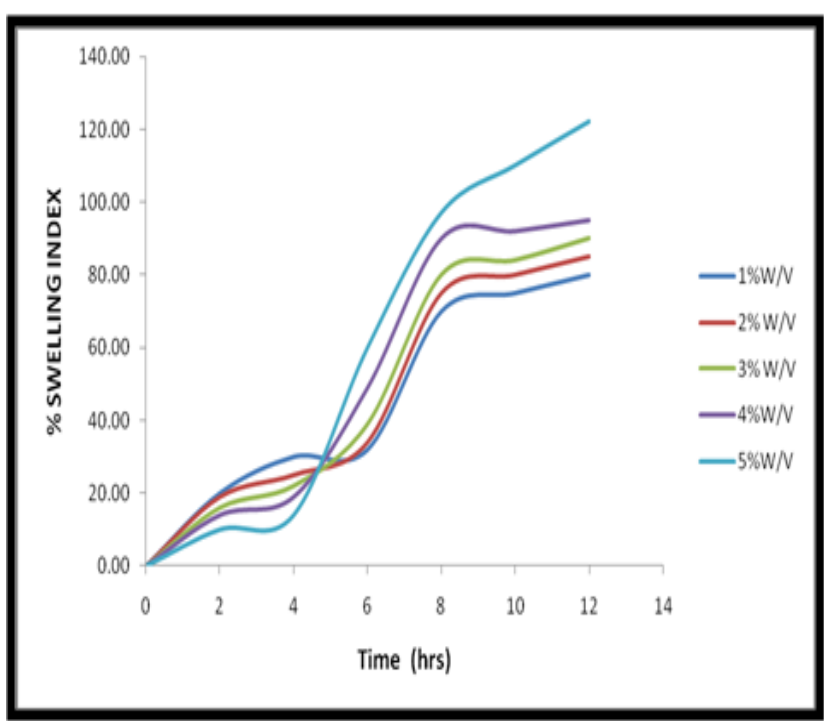

Figure $3 \%$ swelling index of Eudragit $\mathrm{S}-\mathrm{I} 00(\mathrm{I}-5 \% \mathrm{w} / \mathrm{v})$ in different $\mathrm{pH}$ conditions.

The formulation F4, F5 and F6 (Chitosan+ Sodium Alginate) showed a significant sustained release profile as like Xanthan gum based formulation. The formulation F4 having the ratio of oppositely charged ions (50mg Chitosan $+10 \mathrm{mg}$ sodium alginate), exhibited $98.44 \%$ drug release in $15 \mathrm{~h}$. Whereas F5 Formulation (50mg Chitosan+20mg sodium alginate $+50 \mathrm{mg}$ L.P) showed $98.92 \%$ drug released in $15 \mathrm{hrs}$. The formulation F6 in $15 \mathrm{hrs}$ released the drug upto $93.45 \%$ only which might be the case of stronger polyelectrolyte charge interactions. So among all the formulations it was observed that F5 formulation was found to be the best formulation has been shown in Figure 4 . The percentage cumulative drug release has been shown in the Table 5.

\section{Drug release kinetics}

The release profiles of the developed formulations were fitted with various pharmacokinetics models in order to assess the sustained 
release pattern and mechanism of drug release. Result demonstrated that F1 and F2 formulation followed the zero order kinetics; F3 formulation followed the Krosmeyer-Peppas model for drug release indicating the drug release behaviour from swellable polymers. Formulations F4, F5 and F6 were found to be following first order kinetics. Results of the kinetic analysis of drug release indicated that the most predominant release mechanism was first order " $n$ " values of between 1.65-2.01 which implies super case II release kinetics. This indicated that the release of drug from all formulations followed the mechanism of sustain release. The results of the curve fitting into

Table 2 Pre-compression parameters of powdered materials these above mentioned mathematical models has been shown in Table 6.

\section{Stability study}

The stability studies of the best formulation was known by performing stability studies for three months at accelerated conditions of $40^{\circ} \mathrm{C} \pm 75 \% \mathrm{RH}$ on optimized formulation. The formulation was found to be stable, with insignificant change in the drug content and in-vitro drug release pattern the data has been given in Table 7 .

\begin{tabular}{llllll}
\hline Batch no. & Bulk density & Tapped density & Carr's index & Hausner's ratio & Angle of repose \\
\hline FI & $0.172 \pm 0.0005$ & $0.193 \pm 0.002$ & 10.8 & 1.12 & $19.5^{\circ}$ \\
F2 & $0.177 \pm 0.001$ & $0.195 \pm 0.002$ & 9.2 & 1.1 & $19.7^{\circ}$ \\
F3 & $0.173 \pm 0.001$ & $0.183 \pm 0.001$ & 5.46 & 1.05 & $19^{\circ}$ \\
F4 & $0.183 \pm 0.002$ & $0.189 \pm 0.01$ & 3.176 & 1.03 & $18.5^{\circ}$ \\
F5 & $0.2 \pm 0.006$ & $0.218 \pm 0.001$ & 8.25 & 1.09 & $18.7^{\circ}$ \\
F6 & $0.185 \pm 0.001$ & $0.216 \pm 0.001$ & 14.76 & 1.16 & $18.9^{\circ}$ \\
\hline
\end{tabular}

Table 3 Results for determination of \% swelling index

\begin{tabular}{llllll}
\hline Time (hr) & \multicolumn{4}{l}{ Concentration } \\
\cline { 2 - 6 } & $\mathbf{I} \mathbf{W} / \mathbf{V}$ & $\mathbf{2} \% \mathbf{W} / \mathbf{V}$ & $\mathbf{3} \% \mathbf{W} / \mathbf{V}$ & $\mathbf{4} \% \mathbf{W} / \mathbf{V}$ & $\mathbf{5 \%} \mathbf{W} / \mathbf{V}$ \\
\hline 2 & $20 \pm 0.5$ & $19 \pm 0.26$ & $16 \pm 0.5$ & $14 \pm 0.05$ & $10 \pm 0.1$ \\
4 & $30 \pm 0.75$ & $25 \pm 1.10$ & $22 \pm 0.9$ & $19 \pm 0.2$ & $14 \pm 0.02$ \\
6 & $32 \pm 0.208$ & $34 \pm 0.5$ & $39 \pm 1.5$ & $49 \pm 0.7$ & $60 \pm 0.3$ \\
8 & $70 \pm 0.11$ & $75 \pm 0.1$ & $80 \pm 0.7$ & $90 \pm 0.29$ & $97 \pm 0.31$ \\
10 & $75 \pm 0.15$ & $80 \pm 0.6$ & $84 \pm 0.9$ & $92 \pm 0.32$ & $110 \pm 0.11$ \\
12 & $80 \pm 0.702$ & $85 \pm 0.8$ & $90 \pm 0.3$ & $95 \pm 0.5$ & $122 \pm 0.5$ \\
\hline
\end{tabular}

Table 4 Percentage Drug content, thickness, Average weight

\begin{tabular}{llll}
\hline Formulations & Drug content $(\%)$ & Thickness $(\mathbf{m m})$ & Average $\mathbf{W t}(\mathbf{m g})$ \\
\hline FI & $99.36 \pm 0.20$ & $2.34 \pm 0.045$ & $258 \pm 0.1$ \\
F2 & $98.80 \pm 0.20$ & $2.5 \pm 0.02$ & $271 \pm 0.1$ \\
F3 & $101.48 \pm 0.40$ & $2.39 \pm 0.055$ & $287 \pm 0.85$ \\
F4 & $100.32 \pm 0.2$ & $2.2 \pm 0.6$ & $233 \pm 0.6$ \\
F5 & $101.96 \pm 0.42$ & $2 \pm 0.30$ & $254 \pm 0.1$ \\
F6 & $100.20 \pm 0.74$ & $3.2 \pm 0.25$ & $272 \pm 1.1$
\end{tabular}

Table 5 Results for determination of drug release profile

\begin{tabular}{|c|c|c|c|c|c|c|}
\hline \multirow[t]{2}{*}{ Time (hr) } & \multicolumn{6}{|c|}{ Formulation } \\
\hline & FI (\%) & F2 (\%) & F3 (\%) & F4 (\%) & F5 (\%) & F6 (\%) \\
\hline I & $1.35 \pm 0.015$ & $1.3 \pm 0.02$ & $1.4 \pm 0.02$ & $1.33 \pm 0.015$ & $\mid .5 I \pm 0.01$ & $1.53 \pm 0.05$ \\
\hline 2 & $1.44 \pm 0.02$ & $1.4 \pm 0.02$ & $1.54 \pm 0.035$ & $1.47 \pm 0.02$ & $1.87 \pm 0.5$ & $1.9 \pm 0.3$ \\
\hline 3 & $4.6 \pm 0.5$ & $4.50 \pm 0.02$ & $4.58 \pm 0.05$ & $4.6 \pm 0.5$ & $4.8 \pm 0.32$ & $4.75 \pm 0.5$ \\
\hline 4 & $5.77 \pm 0.47$ & $5.64 \pm 0.6$ & $5.4 I \pm 0.3$ & $5.34 \pm 0.02$ & $5.46 \pm 0.42$ & $5.2 \pm 0.29$ \\
\hline 5 & $24.5 \pm 0.12$ & $8.9 \pm 0.19$ & $8.38 \pm 0.2$ & $25.3 \pm 0.5$ & $19.08 \pm 0.2$ & $15.96 \pm 0.32$ \\
\hline 6 & $40.86 \pm 0.2$ & $22.32 \pm 0.2$ & $12 \pm 0.09$ & $60.84 \pm 0.25$ & $39.47 \pm 0.5$ & $34.38 \pm 0.30$ \\
\hline
\end{tabular}




\begin{tabular}{lllllll}
\multicolumn{6}{l}{ Table Continued.. } \\
\hline Time (hr) & \multicolumn{7}{l}{ Formulation } & & & & \\
\cline { 2 - 7 } & FI (\%) & F2 (\%) & F3 (\%) & F4 (\%) & F5 (\%) & F6 (\%) \\
\hline 7 & $51.66 \pm 0.6$ & $31.86 \pm 0.5$ & $14.94 \pm 0.5$ & $73.8 \pm 0.5$ & $77.94 \pm 0.32$ & $51.84 \pm 0.6$ \\
8 & $62.98 \pm 0.02$ & $59.76 \pm 0.01$ & $27.9 \pm 0.12$ & $81.55 \pm 0.52$ & $89.46 \pm 0.2$ & $66.96 \pm 0.31$ \\
9 & $73.44 \pm 0.5$ & $72.9 \pm 0.015$ & $49.32 \pm 0.40$ & $87.52 \pm 0.1$ & $92.21 \pm 0.43$ & $74.82 \pm 0.1$ \\
10 & $78.84 \pm 0.01$ & $73.96 \pm 0.2$ & $68.9 \pm 0.62$ & $92.56 \pm 0.56$ & $95.46 \pm 0.6$ & $81.18 \pm 0.52$ \\
11 & $84.31 \pm 0.5$ & $75.48 \pm 0.74$ & $72.15 \pm 0.5$ & $97.21 \pm 0.4$ & $96.98 \pm 0.46$ & $89.21 \pm 0.5$ \\
12 & $91.02 \pm 0.02$ & $82.71 \pm 0.2$ & $84.56 \pm 1.12$ & $97.34 \pm 0.08$ & $98.82 \pm 0.06$ & $92.52 \pm 0.2$ \\
13 & $95.64 \pm 0.20$ & $91.44 \pm 0.5$ & $95.52 \pm 0.18$ & $98.01 \pm 0.09$ & $98.89 \pm 0.5$ & $93.36 \pm 0.42$ \\
14 & $95.64 \pm 0.15$ & $91.46 \pm 0.06$ & $95.54 \pm 0.06$ & $98.42 \pm 0.05$ & $98.92 \pm 0.8$ & $93.45 \pm 0.71$ \\
15 & $95.65 \pm 0.01$ & $91.47 \pm 0.2$ & $95.54 \pm 0.65$ & $98.44 \pm 0.43$ & $98.92 \pm 0.9$ & $93.45 \pm 0.64$
\end{tabular}

Table 6 Regression coefficient (R2) values of the analysis of release data as per various kinetic model

\begin{tabular}{lllllll}
\hline Formulation & Zero order kinetics & First order kinetics & Hixson & Higuchi & \multicolumn{2}{l}{ Krosmeyer } \\
\cline { 2 - 7 } & $\mathbf{R}^{2}$ & $\mathbf{R}^{2}$ & $\mathbf{R}^{2}$ & $\mathbf{R}^{2}$ & $\mathbf{R}^{2}$ & $\mathbf{n}(\mathbf{v a l u e})$ \\
\hline FI & 0.96 & 0.926 & 0.184 & 0.942 & 0.907 & 2.014 \\
F2 & 0.937 & 0.908 & 0.105 & 0.892 & 0.903 & 1.77 \\
F3 & 0.912 & 0.775 & 0.126 & $0.7 I I$ & 0.92 & 1.65 \\
F4 & 0.88 & 0.953 & 0.309 & 0.828 & 0.832 & 1.95 \\
F5 & 0.865 & 0.939 & 0.34 & 0.801 & 0.875 & 1.95 \\
F6 & 0.938 & 0.939 & 0.12 & 0.826 & 0.876 & 1.86 \\
\hline
\end{tabular}

Table 7 Stability studies of drug content and drug release parameters

\begin{tabular}{|c|c|c|c|c|c|c|c|c|}
\hline \multirow[t]{3}{*}{ Parameters } & \multicolumn{8}{|c|}{ Time in months } \\
\hline & \multicolumn{4}{|c|}{ Formulation F5 } & \multicolumn{4}{|c|}{ Formulation F4 } \\
\hline & Initial & $I^{\text {st }}$ month & $2^{\text {nd }}$ month & $3^{\text {rd }}$ month & Initial & Ist month & $2^{\text {nd }}$ month & $3^{\text {rd }}$ month \\
\hline Drug content (\%) & 101.96 & $101.20 \pm 0.7$ & $100.45 \pm 0.05$ & $99.77 \pm 0.32$ & 100.32 & $99.35 \pm 0.1$ & $99.30 \pm 0.08$ & $98.89 \pm 1.12$ \\
\hline Drug release (\%) & 98.92 & $97.90 \pm 0.42$ & $97.58 \pm 0.12$ & $97.36 \pm 0.4$ & 98.44 & $97.21 \pm 0.7$ & $97.01 \pm 1.4$ & $96.79 \pm 0.62$ \\
\hline
\end{tabular}

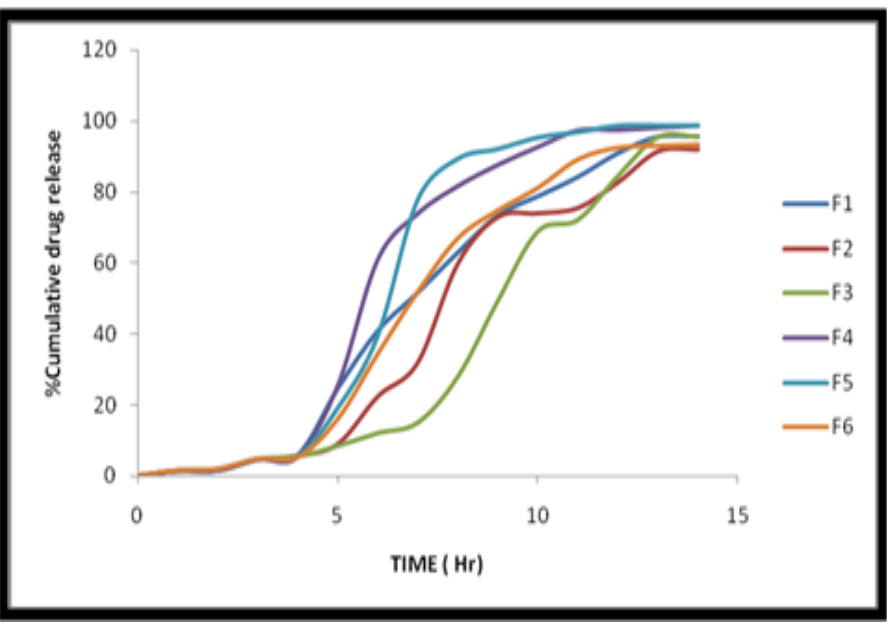

Figure 4 Percent cumulative drug release profile from different polyelectrolyte complexes of LP.

\section{Conclusion}

Targeted drug delivery to the colon is highly desirable for local treatment of a variety of bowel diseases such as (ulcerative colitis, crohn's disease) amebiosis, colonic cancer, and for local treatment of local colonic pathologies, and the systemic delivery of protein and peptide drugs. The colon specific drug delivery system (CDDS) should be capable of protecting the drug en route to colon i.e. drug release and absorption should not occur in the stomach as well as the small intestine and bioactive agent should not be degraded and to allow drug release only in the colon .This study was conducted to developed a colon specific polyelectrolyte complexation based formulation of LP using the concept of polyelectrolyte complexation (PEC). LP capsules containing the PEC of cationic (Chitosan) and anionic (Sodium alginate/Xanthan gum) oppositely charged polyions were used and these capsules were coated with Eudragit S 100 (1$5 \% \mathrm{w} / \mathrm{v})$ along with PEG and Talc $(0.5 \%)$ were able to retard the release of drug in the upper GI tract. Percent swelling index suggested that Eudragit S-100 at 5\% w/v concentration was found to have best percent swelling index accounting to highest value of $122 \%$ after 
twelve hours of study. In vitro release studies showed a sustained release profile over the span of $15 \mathrm{hrs}$ in 7.4 phosphate buffer. This study also concluded that sustained release of drug is dependent on the presence of PEC C+SA/X. From the In-vitro drug release study it was found that the highest drug release was observed i.e $98.92 \%$ from the $\mathrm{F} 5$ formulation having $\mathrm{C}+\mathrm{SA}(50 \mathrm{mg}+20 \mathrm{mg})$ in $15 \mathrm{hrs}$ at pH 7.4 phosphate buffer. From the result of release kinetics the data were best fitted with the first order kinetics with super case II release kinetics. The above study has shown that PECs based on C and SA has been exploited successfully for colon-targeted delivery of LP in the treatment of Hypertension.

\section{Acknowledgements}

The authors are thankful to ZIM Laboratories Nagpur, India for providing us Losartan Potassium as a gift sample. We are also thankful to Evonik, India for providing us Eudragit S-100 as a generous gift. Moreover the authors feel immense pleasure in acknowledging the support of the management of Invertis University where all the work has been performed.

\section{Conflict of interest}

The author declares no conflict of interest.

\section{References}

1. Sharma N, Harikumar SLR. Polymers for Colon Targeted Drug Delivery: A Review. Int J Drug Dev Res. 2013;5(1):21-31.

2. Kaur J, Harikumar SL. Interpolyelectrolyte complex as prospective carrier for controlled drug delivery. Int Res J Pharm. 2012;3(4):58-62.

3. Andreas FT, Martin M, Herbert D, et al. Polyelectrolyte Complexes Adv Polym Sci. 2004;166:113-171.

4. Delair T. Colloidal polyelectrolyte complexes of chitosan and dextran sulphate towards versatile nanocarriers of bioactive molecules. Eur $J$ Pharm Biopharm. 2011;78(1):10-18.

5. Kindermann C, Matthée K, Strohmeyer J, et al. Tailor made release from hot-melt extruded complexes of basic polyelectrolyte and poorly water-soluble drugs. Eur J pharm biopharm. 2011;79(2):372-381.
6. Roy K, Mao HQ, Huang SK, et al. Oral gene delivery with chitosanDNA nanoparticles generates immunologic protection in a murine model of peanut allergy. Nat Med. 1999;5(4):387-391.

7. European Pharmacopoeia. 4th ed. 2002;(Supplement 4.2):293.

8. Israili ZH. Clinical pharmacokinetics of angiotensin II (AT1) receptor blockers in hypertension. J Hum Hypertens. 2000;14(Suppl 1):S73-S86.

9. Arunachalam A, Mazumder A. The outcome of formulation and in vitro release studies of Levothyroxine sodium tablets. Asian J Pharm Sci Techno. 2011;1(1):33-39.

10. Leon Lachaman, Lieberman HA, Kanig JL. The theory and practice of industrials pharmacy. 3rd ed. Varghese publication house, Mumbai, India; 2009. 293:317-324.

11. USP-XXIX. United State Pharmacopeia and national formulary (USPNF) general chapter $<1174>$ powder flow. RockVille, United States. Pharmacopoeial commission. 2006;28(2):618.

12. Indian Pharmacopoeia. 5th ed. Govt. of India, Ministry of Health and Family Welfare, New Delhi, India; 2016. p. 1-60.

13. Patil GB, Singh SS, Ketan P, et al. Design and development of novel dual-compartment capsule for improved gastroretention. ISRN Pharmaceutics. 2012;2013 (2013):1-7.

14. Mundargi RC, Patil SA, Agnihotri SA, et al. Development of polysaccharide-based colon targeted drug delivery systems for the treatment of amoebiasis. Drug Dev Ind Pharm. 2007;33(3):255-264.

15. https://www.google.co.in/amp/s/beautifultf.wordpress. com/2013/12/21/experiment-3-uniformity-of-weight-of-tablets-andcapsule/amp/

16. Indian Pharmacopoeia. Controller of Publications, Govt. of India, Ministry of Health \& Family Welfare, New Delhi; 1996. 135 p.

17. Newton AMJ, Kaur B, Indana VL, et al. Chronotherapeutic drug delivery of pectin vs. guar gum, xanthan gum controlled release colon targeted directly compressed propranolol Hcl matrix tablets. SAJ Pharm Pharmacol. 2014;1:201.

18. Chaturvedi S, Agarwal VK, Singh S. Impact of superdisintegrants on the release of oro-dispersible tablets of losartan potassium: A comparative analysis. Scholars Research Library, Der Pharmacia Lettre. 2012;4(6):1768-1776. 